\title{
Simultaneous Dieulafoy's lesion and marginal ulcer in gastric bypass patient
}

\author{
Vinay S Gundlapalli, Arunkumar Baskara, Susan Suozzo, \\ Brandon Oconnell
}

\begin{abstract}
Introduction: Dieulafoy's lesion is one of the rare causes for gastrointestinal hemorrhage. Marginal ulcer is an anastamotic ulcer in the gastric pouch of a gastric bypass patient is a common cause gastrointestinal hemorrhage. Case Report: We report a case of 27-year-old female who had undergone laparoscopic gastric bypass surgery who presented with gastrointestinal hemorrhage. Upper gastrointestinal endoscopy demonstrated a Dieulafoy's lesion and a marginal ulcer in the gastric pouch. The Dieulafoy's lesion was successfully managed with epinephrine injection and clip application. The marginal ulcer was not the bleeding source. Conclusion: To our knowledge this is the first reported case of simultaneous Dieulafoy lesion and marginal ulcer in a gastric pouch of a gastric bypass patient.
\end{abstract}

Keywords: Dieulafoy's lesion, Marginal ulcer, Gastric bypass, Gastrointestinal hemorrhage

$* * * * * * * * *$

Gundlapalli VS, Baskara A, Suozzo S, Oconnell B. Simultaneous Dieulafoy's lesion and marginal ulcer in

Vinay S Gundlapalli1 ${ }^{1}$, Arunkumar Baskara' ${ }^{1}$, Susan Suozzo², Brandon Oconnell ${ }^{3}$

Affiliations: ${ }^{1} \mathrm{MD}$ MRCS, Mercy Catholic Medical Center, Philadelphia, ${ }^{2} \mathrm{MA}$, Kansas City University of Medicine and Biosciences, ${ }^{3}$ FACS, Mercy Catholic Medical Center, Philadelphia

Corresponding Author: Dr. Vinay S Gundlapalli, Address: 778 Providence Rd, Lansdowne towers appt 109 B, Aldan, PA 19018; Ph: 2154953783; Email: vinaygsagar@gmail.com

Received: 03 April 2012

Accepted: 13 October 2012

Published: 01 June 2013 gastric bypass patient. International Journal of Case Reports and Images 2013;4(6):299-302.

$* * * * * * * * *$

doi:10.5348/ijcri-2013-06-317-CR-2

\section{INTRODUCTION}

Dieulafoy's lesion is a rare cause of gastrointestinal hemorrhage and may be difficult to recognize. It consists of an arteriole that protrudes through a solitary, tiny mucosal defect, usually within $6 \mathrm{~cm}$ of the gastroesophageal junction on the lesser curve of the stomach. Marginal ulcer is a common reason for gastrointestinal hemorrhage in gastric bypass patients. We report an interesting case of gastrointestinal hemorrhage secondary to a Dieulafoy's lesion in the gastric pouch of a Roux-en-Y gastric bypass at the same time this patient also had a marginal ulcer in the gastric pouch.

\section{CASE REPORT}

A 27-year-old African-American female with a history of morbid obesity, she underwent laparoscopic gastric Roux-en-Y bypass surgery one year ago, presented to the emergency room with a two-day history of melena associated with abdominal pain, nausea, and hematemesis. She did not have history of smoking or alcohol abuse. Her only medication was acetaminophen/diphenhydramine (Excedrin) for migraine headaches. Her hemoglobin $(\mathrm{Hb})$ on admission was $7.7 \mathrm{mg} / \mathrm{dL}$. She was symptomatic with tachycardia and weakness. She received a unit of packed red cells. Her hemoglobin increased to $8.4 \mathrm{mg} / \mathrm{dL}$ after transfusion. The next day she had further episodes of hematemesis and melena with a hemoglobin drop to 7.0 $\mathrm{mg} / \mathrm{dL}$. She had an upper gastrointestinal endoscopy and antral biopsy prior to the bypass procedure, which showed erosive esophagitis. 
During the current admission, she underwent an upper gastrointestinal endoscopy, which showed a marginal ulcer (Figure 1) of about $1.5 \mathrm{~cm}$ in diameter on the jejunal side of gastrojejunal anastomosis and a bleeding Dieulafoy's lesion of about $3 \mathrm{~mm}$ (Figure 2) in the gastric pouch. The bleeding Dielufoy's lesion was controlled with epinephrine injection, electrocautry and endoclip application. A total of $18 \mathrm{~mL}$ of $1: 10,000$ epinephrine solution was injected around the lesion and then the lesion was cauterized with bipolar electrocoagulation (BICAP) electrocautery at 17 watts setting (Figure 3). There was still some mild ooze, so two endoclips were applied onto this area with excellent hemostasis. Her hemoglobin was stable at $9 \mathrm{mg} / \mathrm{dL}$ after the procedure and was started on diet which she tolerated. She was discharged home with proton pump inhibitors. Her follow-up visit in the clinic after couple weeks was unremarkable with no abdominal pain, hematemesis or melena with a stable hemoglobin of $9.4 \mathrm{mg} / \mathrm{dL}$.

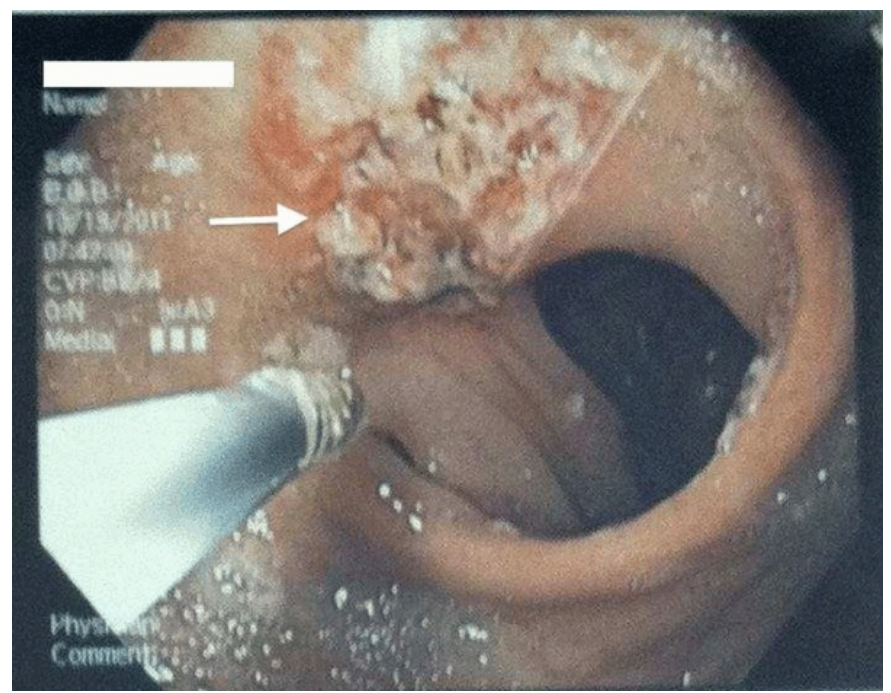

Figure 1: Endoscopic view marginal ulcer arrow.

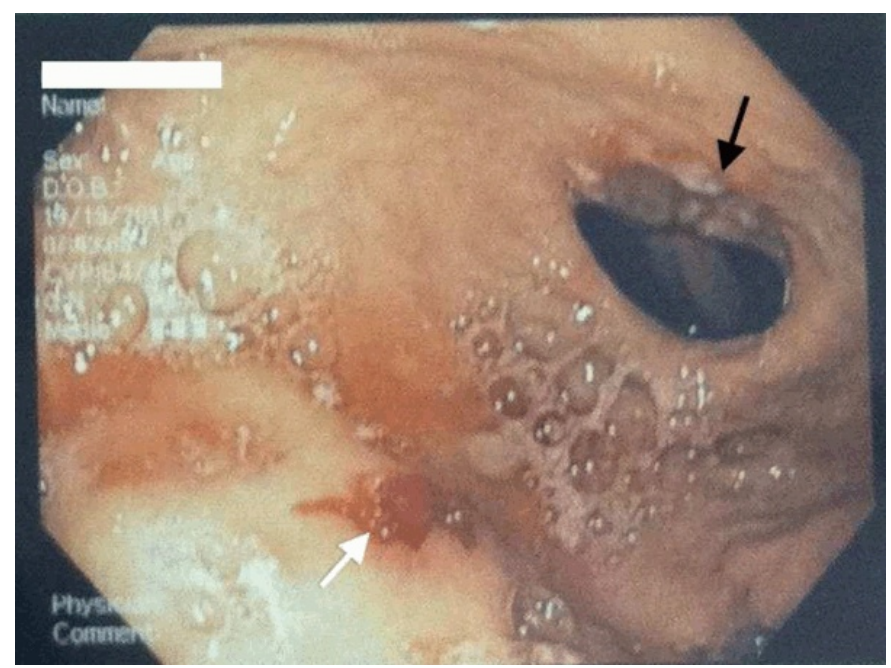

Figure 2: Endoscopic view Dieulafoy lesion (white arrow) marginal ulcer black arrow.

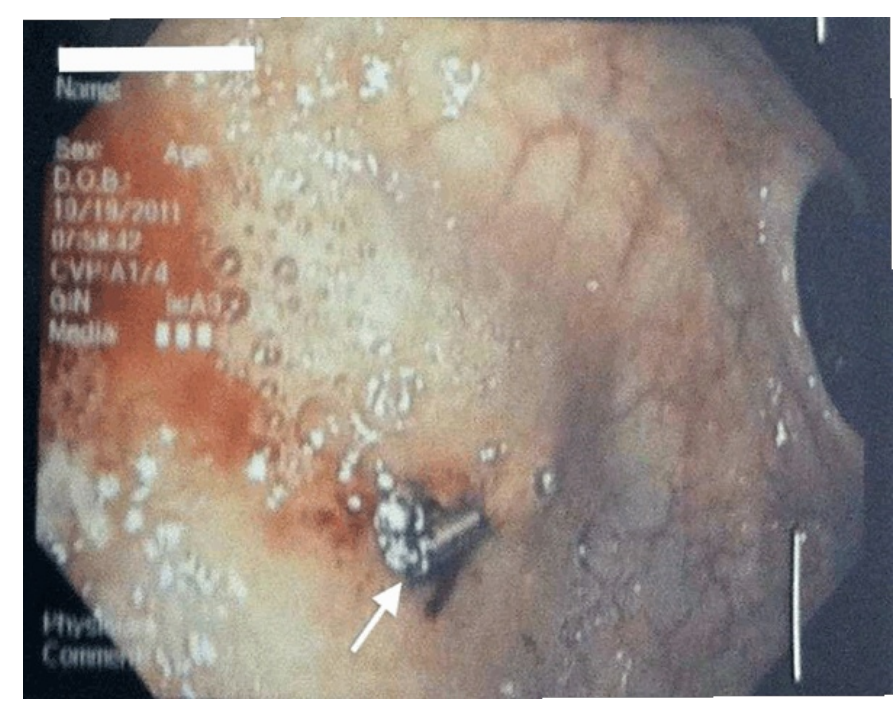

Figure 3: Endoscopic view after epinephrine injection and clip application.

Patient had uneventful hospital course after the procedure.

\section{DISCUSSION}

Dieulafoy's lesion was first described by Galland in 1884 , and he described three cases of these lesions in 1898 [1]. Dieulafoy called the lesion "exulceratio simplex" because of the small size and the large, histologically normal underlying artery. In approximately 4-9\% of massive upper gastrointestinal hemorrhage, no demonstrable cause can be found [2-5]. Dieulafoy's lesion is thought to be the cause of $1-2 \%$ of such cases. A Dieulafoy's lesion is a difficult lesion to recognize, especially when bleeding is inactive.

Therapeutic endoscopy is the initial treatment of choice. The first endoscopic intervention is successful in $85 \%$ of patients, while $10 \%$ of patients need a repeat endoscopy, and $5 \%$ of patients may require surgical intervention $[6,7]$.

Marginal ulcer is an anastmotic ulcer seen at the gastrojejunostomy site of the gastric bypass. This is one of the frequently occurring complications after gastric bypass surgery. The incidence of marginal ulcer has been quoted between $2-20 \%$ in literature. The etiology is not very well understood. The presence of certain risk factors such as smoking, NSAID, steroids, increased acid and $H$. pylori infection have been suggested to increase the incidence. Patients may present with epigastric pain, nausea, vomiting or upper gastrointestinal bleeding. The treatment of marginal ulcer is usually conservative with mucosal protection, proton pump inhibitors and $\mathrm{H}$. pylori eradication. Endoscopic evaluation is diagnostic as well as therapeutic. Surgical intervention is required for failure of conservative management and perforation. 
This case demonstrates the diagnosis and successful endoscopic management of these rare lesions. Although Dieulafoy's lesions are rare, they are an important and potentially life-threatening cause of gastrointestinal hemorrhage. There has been no documented association between Roux-en-Y gastric bypass and Dieulafoy's lesions so far but if there is any, will be a question that remains to be answered.

\section{CONCLUSION}

To our knowledge this is the first time the combination of Dieulafoy's lesion and marginal ulcer has ever been reported in a gastric bypass patient. Careful evaluation of a gastric pouch is very important during an endoscopy for upper gastrointestinal bleeding as small Dieulafoy's lesions can be very easily missed.

\section{Acknowledgements}

We wish to express our sincere thanks to Dr Steven Litchenstein, Head, Department of Gastroenterology, Mercy Catholic Medical Center, Philadelphia.

\section{Author Contributions}

Vinay S Gundlapalli: Substantial contributions to conception and design, Acquisition of data, Analysis and interpretation of data, Drafting the article, Revising it critically for important intellectual content, Final approval of the version to be published

Arun Baskara: Acquisition of data, Analysis and interpretation of data, Drafting the article, Revising it critically for important intellectual content, Final approval of the version to be published

Susan Souzzo: Substantial Acquisition of data, Analysis and interpretation of data, Drafting the article, Revising it critically for important intellectual content, Final approval of the version to be published

Brandon Oconnell: Acquisition of data, Analysis and interpretation of data, Drafting the article, Revising it critically for important intellectual content, Final approval of the version to be published

\section{Guarantor}

The corresponding author is the guarantor of submission.

\section{Conflict of Interest}

Authors declare no conflict of interest.

\section{Copyright}

(C) Vinay S Gundlapalli et al. 2013; This article is distributed under the terms of Creative Commons Attribution 3.0 License which permits unrestricted use, distribution and reproduction in any means provided the original authors and original publisher are properly credited. (Please see www.ijcasereportsandimages.com /copyright-policy.php for more information.)

\section{REFERENCES}

1. Gallard MT. Aneurysmes miliaires de l'estomac. Soc Med Hop Bull Mim Soc Med, Hop 1884:84.

2. Streicher HJ. [Solitary exulceratio simplex (Dieulafoy) as cause of massive intestinal hemorrhage]. Dtsch Med Wochenschr 1966;91(21):991-5.

3. Palmer ED. The vigorous diagnostic approach to upper-gastrointestinal tract hemorrhage. A 23-year prospective study of 1,4000 patients. JAMA 1969;207(8):1477-80.

4. Cotton PB, Rosenberg MT, Waldram RPL, Axon AT. Early endoscopy of oesophagus, stomach, and duodenal bulb in patients with haematemesis and melaena. Br Med J 1973;2(5865):505-9.

5. Margreiter R, Weimann S, Reidler L, Schwamberger K. Die Exulceratio simplex Dieulafoy. Leber Magen Darm 1977;7(6):353-6.

6. Dieulafoy G. L'exulceratio simple. In Manuel de Pathologie Interne. Paris, Masson 1908:178-305.

7. Reilly HF 3rd, Al-Kawas FH. Dieulafoy's lesion. Diagnosis and management. Dig Dis Sci 1991;36(12):1702-7. 
Access full text article on other devices

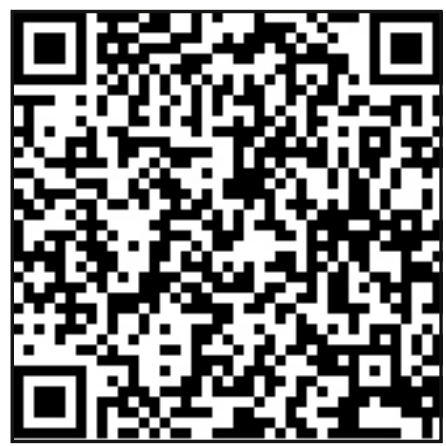

Access PDF of article on other devices

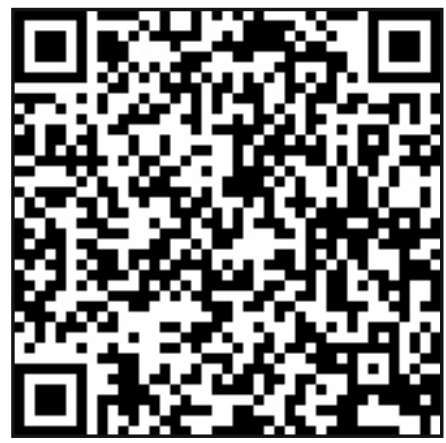

